\title{
Structural, morphological, optical and opto-thermal properties of Ni-doped ZnO thin films using spray pyrolysis chemical technique
}

\author{
S RAJEH ${ }^{1}$, A BARHOUMI ${ }^{1}$, A MHAMDI ${ }^{2, *}$, G LEROY $^{3}$, B DUPONCHEL ${ }^{4}$, M AMLOUK ${ }^{2}$ \\ and S GUERMAZI \\ ${ }^{1}$ Unit of Physics of Insulators Materials and Semi-insulators, Sfax University, B.P. 1171, 3000 Sfax, Tunisia \\ ${ }^{2}$ Unité de physique des dispositifs à semi-conducteurs, Tunis El Manar University, 2092 Tunis, Tunisia \\ ${ }^{3}$ University Lille North of France, ULCO, UDSMM, 62228 Calais, France \\ ${ }^{4}$ University Lille North of France, ULCO, UDSMM, 59140 Dunkerque, France
}

MS received 21 September 2014; accepted 6 July 2015

\begin{abstract}
Nickel-doped zinc oxide thin films ( $\mathrm{ZnO}: \mathrm{Ni})$ at different percentages were deposited on glass substrates using a chemical spray technique. The effect of Ni concentration on the structural, morphological, optical and photoluminescence (PL) properties of the $\mathrm{ZnO}$ : Ni thin films were investigated. X-ray diffraction analysis revealed that all films consist of single phase $\mathrm{ZnO}$ and was well crystallized in würtzite phase with the crystallites preferentially oriented towards the (002) direction parallel to the $c$-axis. The optical transmittance measurement was found to be higher than $90 \%$, the optical band gap values of $\mathrm{ZnO}$ thin films decreased after doping from $3.29 \mathrm{to} 3.21 \mathrm{eV}$. A noticeable change in optical constants was observed between undoped and Ni-doped ZnO. Room-temperature PL is observed for $\mathrm{ZnO}$, and Ni-doped $\mathrm{ZnO}$ thin films.
\end{abstract}

Keywords. Thin films; Ni-doped $\mathrm{ZnO}$; chemical spray; optical properties; photoluminescence; opto-thermal.

\section{Introduction}

Zinc oxide $(\mathrm{ZnO})$ is a wide band gap semiconductor with an energy gap of $3.37 \mathrm{eV}$ at room temperature. As a consequence, $\mathrm{ZnO}$ absorbs UV radiation because of band-to-band transitions. It has been used considerably for semiconducting multilayers [1], photothermal conversion system [2], photocatalytic [3], solar cells [4], gas sensors [5] and transparent electrodes [6]. Among all the oxide materials studied, in the last years, $\mathrm{ZnO}$ emerged as one of the most promising materials owing to its optical and electrical properties, high chemical and mechanical stabilities, together with its abundance in nature, which makes it a lower cost material when compared with the most currently used transparent conductive oxide materials (ITO and $\mathrm{SnO}_{2}$ ).

Many methods have been described in the literature for the production of $\mathrm{ZnO}$ thin films such as sputtering [7,8], thermal evaporation [9], and spray pyrolysis [10] were applied for the production of $\mathrm{ZnO}$. Spray pyrolysis technique is preferred among these techniques since it is cheaper, simpler and more versatile than the others, which allows the possibility of obtaining films with the required properties for different applications as well as large area films.

The n-type semiconductor behaviour is originated by the ionization of excess zinc atoms at interstitial positions and the oxygen vacancies [11]. It is well known that the addition of dopants into a wide gap semiconductor, such as $\mathrm{ZnO}$, can often induce dramatic changes in the optical, electrical

*Author for correspondence (mhaammar@gmail.com) and magnetic properties $[10,12]$. Transition metal elements have been successfully employed as dopants in $\mathrm{ZnO}$ such as $\mathrm{V}, \mathrm{Cu}, \mathrm{Mn}$ and $\mathrm{Ni}$ [13-16]. Ni is an important dopant in the magnetic materials [17-19]. Furthermore, $\mathrm{Ni}^{2+}(0.69 \AA)$ has the same valence compared with $\mathrm{Zn}^{2+}$ and its radius is close to $\mathrm{Zn}^{2+}(0.74 \AA)$, so it is possible for $\mathrm{Ni}^{2+}$ to replace $\mathrm{Zn}^{2+}$ in $\mathrm{ZnO}$ lattice. Some research works on Ni-doped $\mathrm{ZnO}$ showed that the luminescence properties of $\mathrm{ZnO}$ changed after doping of $\mathrm{Ni}$ [20-23].

In this paper, the influence of $\mathrm{Ni}$ doping on the structural, morphological, optical and photoluminescence (PL) properties of $\mathrm{ZnO}$ films is reported.

\section{Experimental}

$\mathrm{Ni}$-doped $\mathrm{ZnO}$ thin films deposited on glass substrates were prepared by the spray pyrolysis technique. Undoped $\mathrm{ZnO}$ thin films were prepared using zinc acetate $\left(\mathrm{C}_{4} \mathrm{H}_{6} \mathrm{O}_{4} \mathrm{Zn} \cdot 2 \mathrm{H}_{2} \mathrm{O}\right)$ dissolved in isopropyl alcohol to obtain a starting solution with a $10^{-1}$ mol $1^{-1}$ concentration.

Doping of $\mathrm{ZnO}$ thin films with nickel was carried out by adding the compound source of $\mathrm{Ni}\left(\mathrm{NiCl}_{2}\right)$ in the starting solution with an atomic percentage $[\mathrm{Ni} / \mathrm{Zn}]=2,3$ and 4 at. $\mathrm{wt} \%$. The resulting solution was stirred at $100^{\circ} \mathrm{C}$ for $20 \mathrm{~min}$ to lead to a clear and homogeneous solution. Glass slides $(2 \mathrm{~cm} \times 1 \mathrm{~cm})$ were used as substrates. Before loading into the system, the substrates were washed with detergent and then completely rinsed in methanol, acetone and finally dried in air. Then the substrates were progressively heated up to the 
required temperature, before being sprayed on. The deposition temperature $T_{\mathrm{s}}$ (temperature at the substrate surface) was maintained at $460^{\circ} \mathrm{C}$.

The structure and the crystallinity of the $\mathrm{ZnO}$ and $\mathrm{Ni}$ doped $\mathrm{ZnO}$ thin films were determined by a copper-source diffractometer (Analytical X Pert PROMPD), with the wavelength $\lambda=1.54056 \AA$. The surface morphology of the films was examined by atomic force microscopy (AFM) and scanning electron microscopy (SEM). AFM experiments were conducted on a Veeco (now Brüker) multimode used in contact mode and SEM observations on a Quanta 200 FEI at 15 and $25 \mathrm{kV}$. In order to determine band gap energy and optical constants of $\mathrm{ZnO}$ and $\mathrm{Ni}$-doped $\mathrm{ZnO}$ in thin films, the optical transmission and absorption were studied in the wavelength range of 200-3000 nm, using a Shimadzu UV3101 PC spectrophotometer.

\section{Results and discussion}

\subsection{Structural properties}

The crystal structures of undoped and $\mathrm{Ni}$-doped $\mathrm{ZnO}$ were studied by means of X-ray diffraction (XRD). Figure 1 shows

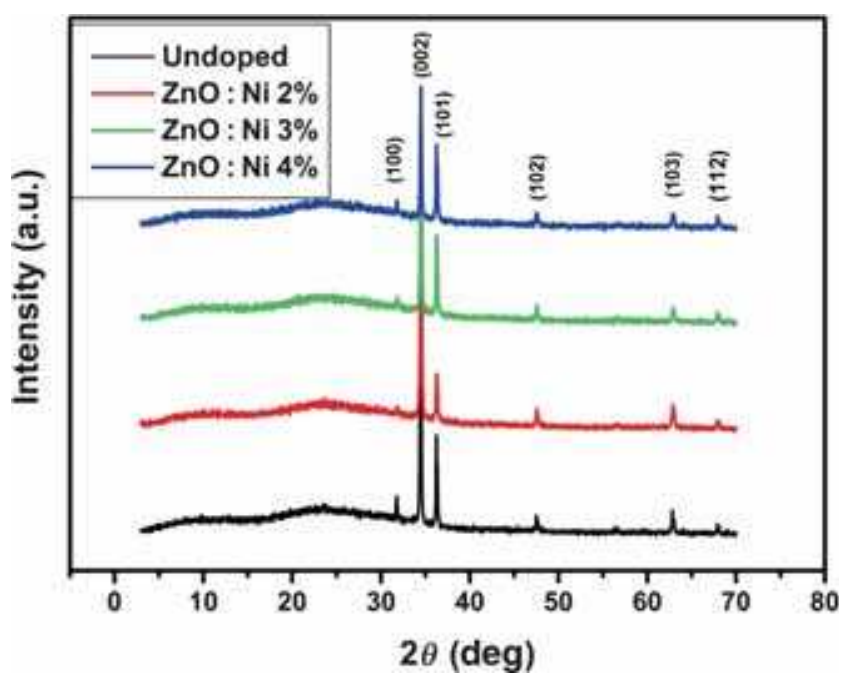

Figure 1. XRD patterns of undoped and Ni-doped sprayed $\mathrm{ZnO}$ thin layers. the XRD patterns of undoped and Ni-doped $\mathrm{ZnO}$. The XRD patterns of these samples are in good agreement with the Joint Committee on Powder Diffraction Standards (JCPDS) (No. 36-1451) data of wurtzite (hexagonal) $\mathrm{ZnO}$ powder. It is observed that undoped and $\mathrm{Ni}$-doped $\mathrm{ZnO}$ samples exhibit peaks corresponding to the (100), (002), (101), (102), (103) and (112) planes, with the (002) peak showing the highest intensity in all cases, implying that all the samples have a hexagonal crystal structure with a preferred orientation with the substrate normal parallel to the normal of the $\mathrm{ZnO}$ (002) plane. The diffraction peaks attributed to Ni-related secondary phases have not been observed. In addition, the position of the $(002)$ peak shifted slightly $\left(\approx 0.03^{\circ}\right)$ from $2 \theta=34.45^{\circ}$ in undoped $\mathrm{ZnO}$ film to higher angles as $\mathrm{Ni}$ content increases $\left(2 \theta=34.48^{\circ}\right.$ for $\left.\mathrm{ZnO}: \mathrm{Ni} 4 \%\right)$, indicating that $\mathrm{Ni}$ ions substitute $\mathrm{Zn}$ ions in the $\mathrm{ZnO}$ lattice owing to the slight difference between the ionic radii of $\mathrm{Ni}^{2+}(0.069 \AA)$ and $\mathrm{Zn}^{2+}(0.74 \AA)$ [24].

The lattice constants can be calculated using the following relation [25]:

$$
\frac{1}{d_{h k l}^{2}}=\frac{4}{3}\left(\frac{h^{2}+h k+k^{2}}{a^{2}}\right)+\frac{l^{2}}{c^{2}},
$$

where $a$ and $c$ are the lattice constants and $d_{h k l}$ the crystalline surface distance for $h k l$ indices. Table 1 lists the calculated values of $d_{h k l}$ and lattice parameters of undoped and $\mathrm{Ni}$-doped $\mathrm{ZnO}$ thin films. It is observed that $d_{h k l}$ values are in good agreement with those reported in JCPDS data cards (No. 36-1451). It can be seen that the interplanar spacing $d_{h k l}$ values decrease with $\mathrm{Ni}$ content. This phenomenon shows that $\mathrm{Ni}$ element used at lower concentrations is introduced in the $\mathrm{ZnO}$ matrix and played an important role in improving the transparency of such doped films [26].

The average crystallite size of undoped and Ni-doped $\mathrm{ZnO}$ is estimated from (002) principal peak by using the DebyeScherrer formula [27]:

$$
D=\frac{H \lambda}{\beta \cos \theta},
$$

where $\lambda=1.5418 \AA$ for $\mathrm{Cu}$ radiation, $\theta$ is the diffraction angle, $K=0.9$ and $\beta$ the full-width at half-maximum (FWHM) with $\beta=\sqrt{\beta_{\mathrm{e}}^{2}-\beta_{0}^{2}}$, where $\beta_{\mathrm{e}}$ is measured from

\begin{tabular}{|c|c|c|c|c|c|c|}
\hline & & \multirow{2}{*}{$\begin{array}{c}\text { Results JCPDS } \\
\text { (pure powder } \mathrm{ZnO} \text { ) }\end{array}$} & \multicolumn{4}{|c|}{ Experiment : Ni content $\mathrm{Ni} / \mathrm{Z}_{n}(\%)$} \\
\hline & & & 0 & 2 & 3 & 4 \\
\hline The position of (002) peak in $2 \theta(\mathrm{deg})$ & & & 34.454 & 34.479 & 34.489 & 34.484 \\
\hline \multirow[t]{2}{*}{ Interplanar spacing $d_{h k \ell}(\AA)$} & $(002)$ & 2.602 & 2.603 & 2.601 & 2.600 & 2.600 \\
\hline & $(101)$ & 2.476 & 2.478 & 2.476 & 2.477 & 2.478 \\
\hline$a(\AA)$ & & 3.249 & 3.254 & 3.252 & 3.253 & 3.254 \\
\hline$c(\AA)$ & & 5.205 & 5.206 & 5.202 & 5.201 & 5.202 \\
\hline$c / a$ & & 1.602 & 1.600 & 1.599 & 1.598 & 1.598 \\
\hline
\end{tabular}

Table 1. Position of the (002) peak and some relevant parameters. 
the film and $\beta_{0}$ corresponds to the reference powder [27,28]. The results are shown in table 2 . As the concentration of $\mathrm{Ni}$ increases, an increase in the crystallite size is observed. The same behaviour is reported by the Muniyandi et al [29] in a study on Ni-doped $\mathrm{ZnO}$ prepared by the spray pyrolysis deposition technique. Muniyandi et al found that the crystallite size increase with the increase in Ni concentration might be due to the agglomeration. This has been further confirmed by the decrease in the value of lattice parameter $c$.

Additional information on structural properties can be obtained from the residual stress measurements calculated by [30].

$$
\sigma=450 \frac{c_{0}-c}{c_{0}},
$$

where $\sigma$ (in GPa) is the mean stress, $c$ the lattice constant of $\mathrm{ZnO}$ thin films and $c_{0}$ the lattice constant of the bulk material (standard $c_{0}=0.5206 \mathrm{~nm}$ ). The calculated data are summarized in table 2. A slight deviation of the (002) peak was revealed when the concentration varied. This indicates that some residual stress inside the film is occurring.

In the same line, the microstrain in these thin films was calculated with the following relation:

$$
\varepsilon_{\mathrm{S}}=\frac{\beta \cos \theta}{4}
$$

where $\theta$ is the (002) diffraction angle. It is noticed that the microstrain of the films decreased when the concentration of $\mathrm{Ni}$ increased (see table 2). This is probably due to the ionic radius of $\mathrm{Zn}^{2+}$ which is higher compared with that of $\mathrm{Ni}^{2+}$ [31].

The preferred orientations of the Ni-doped $\mathrm{ZnO}$ thin films are evaluated by the texture coefficient (TC), calculated from the X-ray data using the well-known formula

$$
\mathrm{TC}(h k l)=\frac{I(h k l) / I_{0}(h k l)}{1 / N \sum_{h k l} I(h k l) / I_{0}(h k l)},
$$

where $\mathrm{TC}(h k l)$ is the texture coefficient of the $h k l$ planes, $I(h k l)$ is the measured or normalized intensity of a plane $(h k l), I_{0}$ the corresponding standard intensity given in JCPDS data, $N$ the number of reflections and $n$ the number of diffraction peaks. The value of TC calculated for the diffraction peaks (002) and (101) of all samples are shown in table 2. From these results, it is observed that $\mathrm{TC}(002)$ is so high, showing that the crystallites are mainly perpendicular to substrate plane (parallel to the $c$-axis) for $\mathrm{ZnO}$ undoped and doped thin films.

\subsection{Surface morphology}

The surface morphology of undoped and Ni-doped $\mathrm{ZnO}$ thin films was characterized by AFM and SEM. Figure 2 shows the typical SEM images of the $\mathrm{ZnO}$ and Ni-doped $\mathrm{ZnO}$ thin films. It is seen grains of about $100 \mathrm{~nm}$ of diameter nearby large plates of several hundred nanometers long. The threedimensional (3D) images of AFM micrographs are shown in figure 3. According to them, grains are clearly spherical and the large plates seen with the SEM seem to be agglomerates of grains. On the AFM pictures, grains appear wider than on SEM images. It is a normal probe-based artefact when measuring globular features. All the films exhibit spherical grains, indicating the polycrystalline nature of these films. The SEM micrographs also reveal that $\mathrm{Ni}$ doping $\mathrm{ZnO}$ thin films can increase the average grain size, this result agrees with XRD measurements. The same behaviour is reported by the Muniyandi et al in a study on $\mathrm{Ni}$-doped $\mathrm{ZnO}$ prepared by the spray pyrolysis deposition technique [29].

In addition, AFM was used to measure the surface roughness of the films over a $2 \mu \mathrm{m} \times 2 \mu \mathrm{m}$ area. The root-mean squares (RMS) roughness of undoped and $\mathrm{Ni}$-doped $\mathrm{ZnO}$ thin films $([\mathrm{Ni}] /[\mathrm{Zn}]=0,0.02,0.03$ and 0.04$)$ are determined as $28.95 ; 28.98 ; 32.30$ and $36.63 \mathrm{~nm}$, respectively. As the $[\mathrm{Ni}] /[\mathrm{Zn}]$ ratio increases, the surface roughness increases as a result of grains increasing caused by the Ni doping and grains agglomeration.

Morphological study reveals that the percentage of dopant has an influence on the morphology and the roughness of the films. However, a slightly tormented surface is quite favourable for the use of such component type in the photovoltaic conversion field.

\subsection{Optical study}

3.3a Optical band-gap: In order to correlate the optical behaviour of films with structural and morphological results, the optical transmittance of samples has been investigated in the wavelength range of $200-3000 \mathrm{~nm}$ using UV-vis

Table 2. Crystallite size $(D)$, texture coefficient (TC), stress $(\sigma)$ and microstrain $\left(\varepsilon_{\mathrm{S}}\right)$ of the sprayed Ni-doped $\mathrm{ZnO}$ thin films.

\begin{tabular}{lcccc}
\hline Samples & $\mathrm{ZnO}$ & $\mathrm{ZnO}: \mathrm{Ni} 2 \%$ & $\mathrm{ZnO}: \mathrm{Ni} 3 \%$ & $\mathrm{ZnO}: \mathrm{Ni} 4 \%$ \\
\hline Peak width at mid-height $\beta(\mathrm{deg})$ & 0.1021 & 0.0836 & 0.0771 & 0.0669 \\
The grain size $D(\mathrm{~nm})$ & 81.61 & 99.57 & 108.11 & 124 \\
$\sigma(\mathrm{GPa})$ & 0 & 0.345 & 0.432 & 0.345 \\
$\varepsilon_{\mathrm{S}}\left(10^{-4}\right)$ & 4.250 & 3.483 & 3.212 & 2.787 \\
TC $(002)$ & 4.727 & 4.401 & 4.744 & 3.894 \\
TC $(101)$ & 0.802 & 0.331 & 0.737 & 0.941 \\
\hline
\end{tabular}



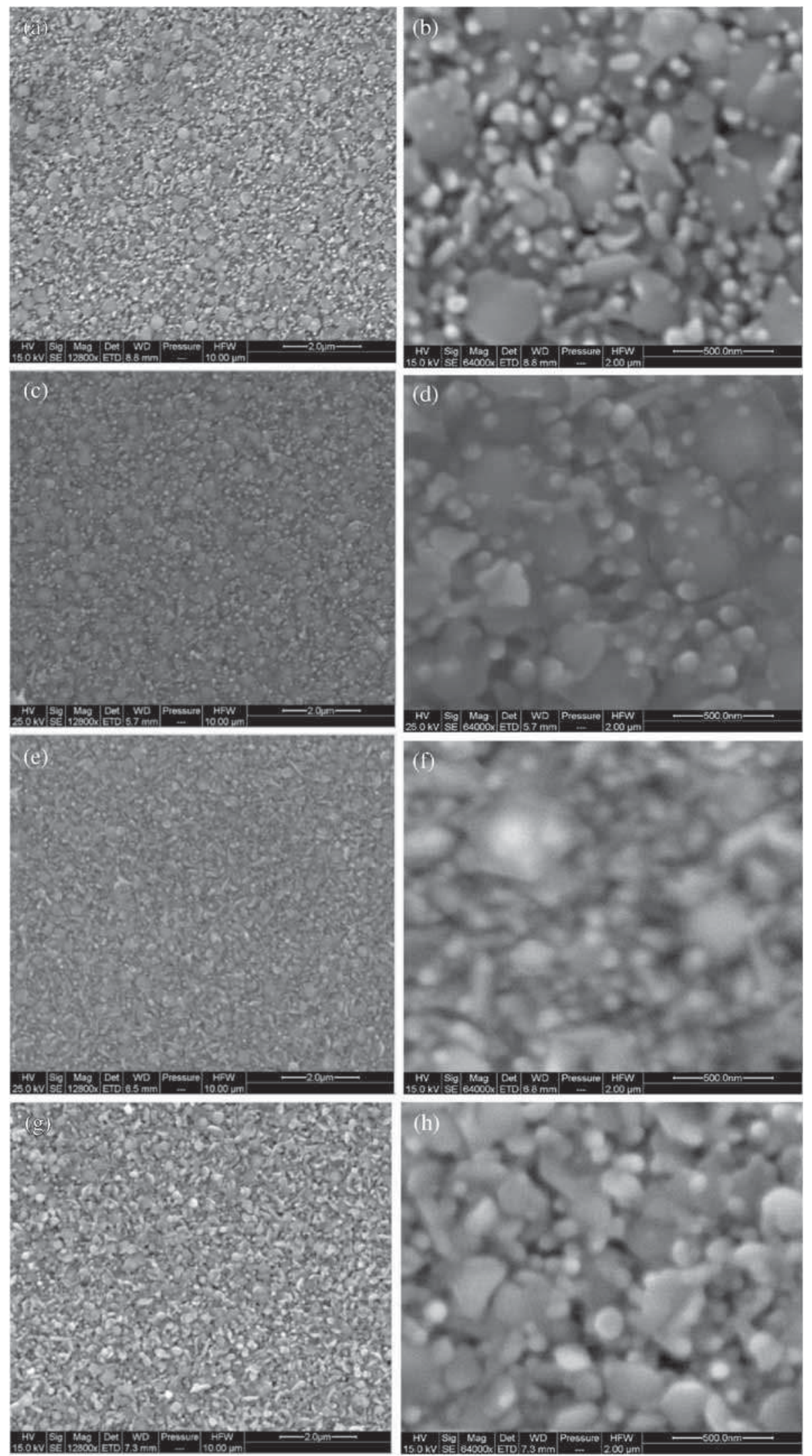

Figure 2. SEM images of pure and $\mathrm{Ni}$-doped $\mathrm{ZnO}$ thin films at low magnification and at high magnification: (a, b) $\mathrm{ZnO},(\mathbf{c}, \mathbf{d}) \mathrm{ZnO}: \mathrm{Ni} 2 \%,(\mathbf{e}, \mathbf{f}) \mathrm{ZnO}: \mathrm{Ni} 3 \%$ and $(\mathbf{g}, \mathbf{h}) \mathrm{ZnO}: \mathrm{Ni} 4 \%$. 


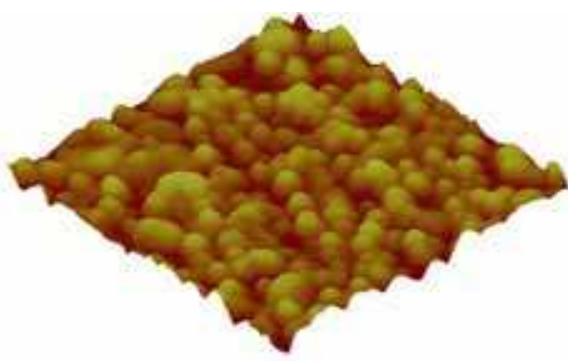

(a) $\mathrm{ZnO}$ pure

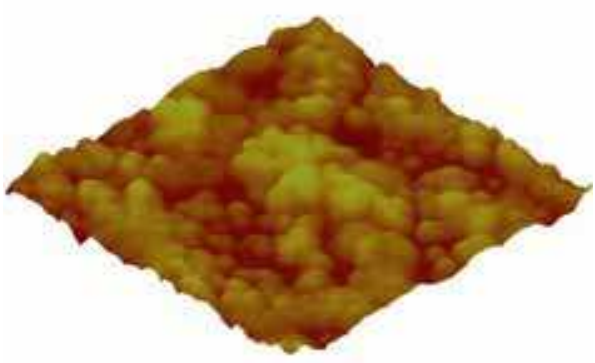

(b) $\mathrm{ZnO}: \mathrm{Ni} 2 \%$

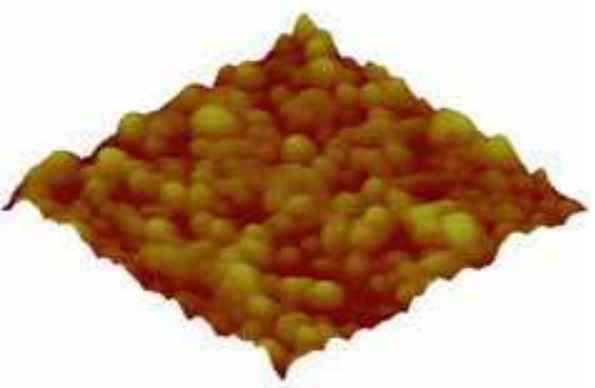

(c) $\mathrm{ZnO}: \mathrm{Ni} 3 \%$

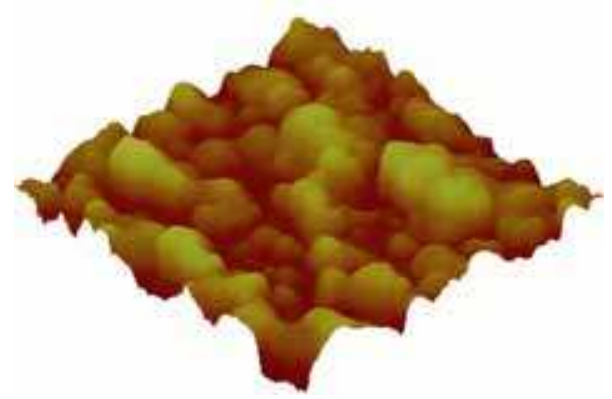

(d) $\mathrm{ZnO}: \mathrm{Ni} 4 \%$

Figure 3. AFM 3D micrographs of sprayed $\mathrm{ZnO}: \mathrm{Ni}$ thin films: (a) $\mathrm{ZnO}$, (b) $\mathrm{ZnO}: \mathrm{Ni} 2 \%$, (c) $\mathrm{ZnO}: \mathrm{Ni} 3 \%$ and (d) $\mathrm{ZnO}: \mathrm{Ni} 4 \%$. Scan area: $2 \mu \mathrm{m} \times 2 \mu \mathrm{m}$. Vertical range: $500 \mathrm{~nm}$.

spectroscopy (figure 4). It is clear from figure 4 that all the samples exhibit a high transmittance around $85 \%$ for $\lambda>$ $625 \mathrm{~nm}$. Some interference fringes appear on all spectra. They are due to multiple reflections from the both sides of the film. From figure 4, it is deduced that all the samples have sharp absorption edges in the wavelength region between 360 and $400 \mathrm{~nm}$. The absorption edge of Ni-doped $\mathrm{ZnO}$ films deposited for different doping concentrations shifts to a larger wavelength. This phenomenon indicates that the optical energy gap decreases with doping concentration. It is well

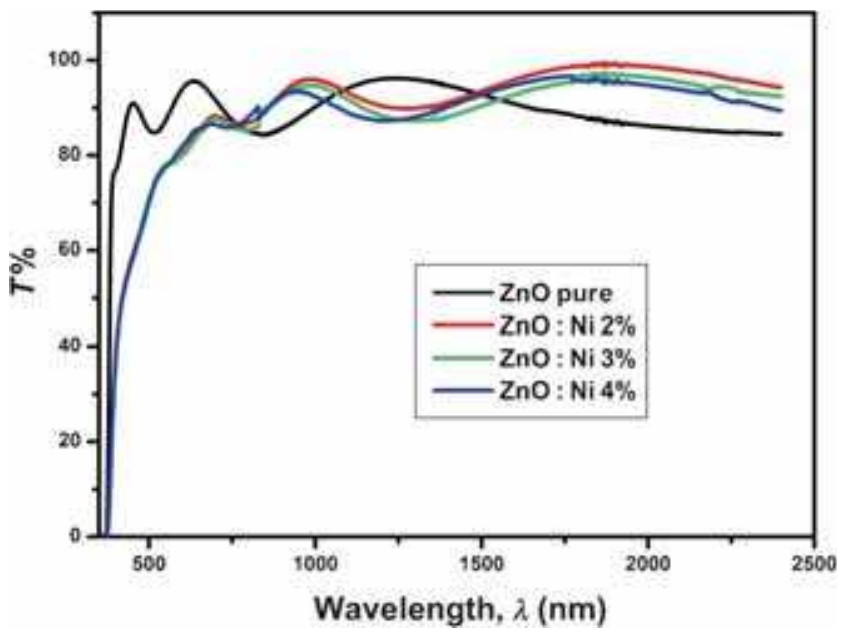

Figure 4. Transmission spectra of sprayed $\mathrm{ZnO}: \mathrm{Ni}$ thin films.

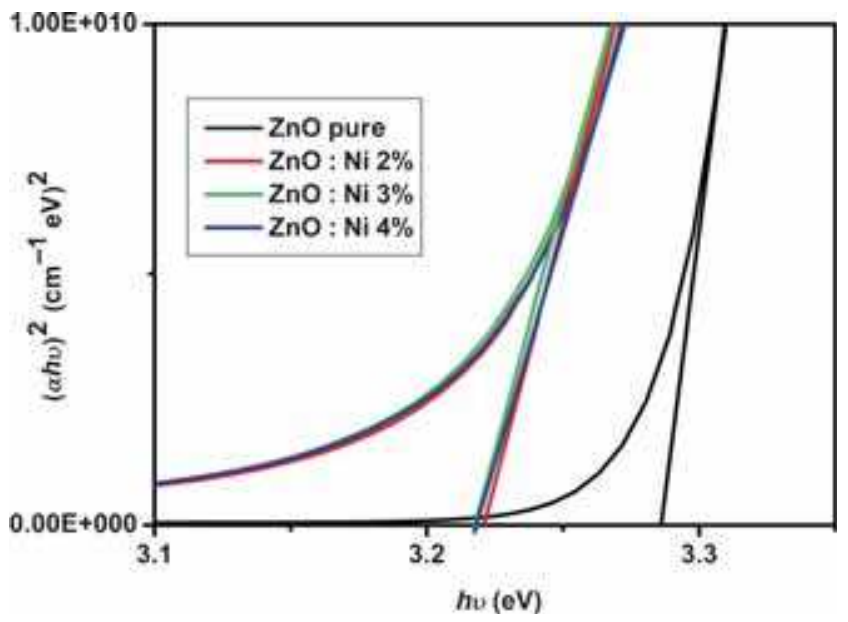

Figure 5. Variation of the absorption as a function of the light energy of sprayed $\mathrm{ZnO}$ : Ni thin films.

known that the theory of optical absorption gives the relation between absorption coefficients $\alpha$ and photon energy $h v$ for direct allowed transition as [32].

$$
\alpha h v=\left[A\left(h v-E_{\mathrm{g}}\right)\right]^{1 / 2},
$$

where $A$ is a constant, $E_{\mathrm{g}}$ the optical band gap energy, $h v$ is the photon energy and $\alpha$ the absorption coefficient. The band gap is determined using this equation when the straight portion of $(\alpha h v)^{2}$ against $h v$ plot is extrapolated to intersect the energy axis at zero. Graph of $(\alpha h v)^{2} v s$. $h v$ for $\mathrm{ZnO}$ and for different $\mathrm{Ni}$ concentrations in $\mathrm{ZnO}$ is shown in figure 5. The obtained band gaps of un-doped $\mathrm{ZnO}, \mathrm{ZnO}: \mathrm{Ni} 2 \%, \mathrm{ZnO}$ : $\mathrm{Ni} 3 \%$ and $\mathrm{ZnO}: \mathrm{Ni} 4 \%$ thin films are 3.29, 3.22, 3.21 and $3.21 \mathrm{eV}$, respectively. It can be seen also that the value of $E_{\mathrm{g}}$ of Ni-doped $\mathrm{ZnO}$ decrease when $\mathrm{Ni}$ concentration increases. It might be due to the increase in the grain size [33] as well as due to the lowering of the conduction band induced by donor level created by the $\mathrm{Ni}$ defects [34]. 


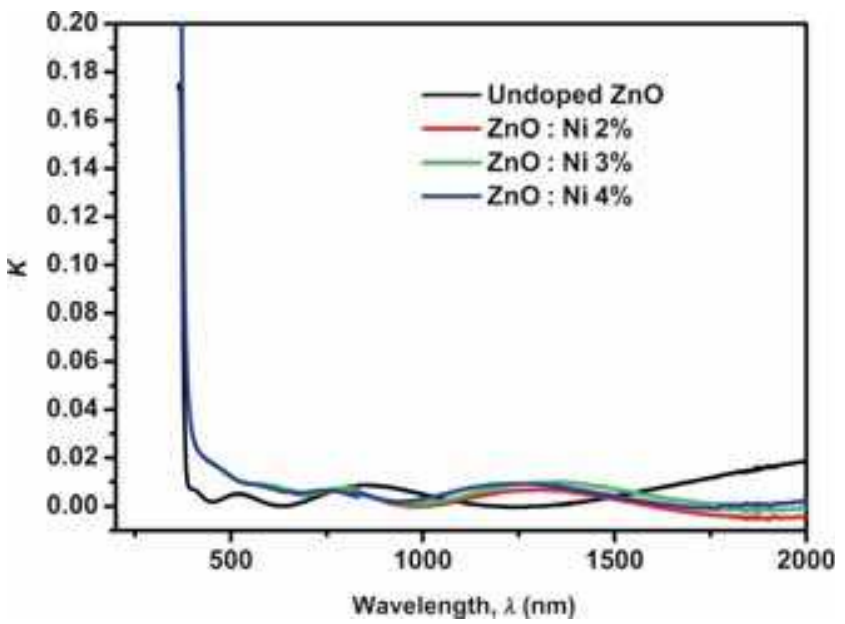

Figure 6. Extinction coefficient $k$ of sprayed $\mathrm{ZnO}: \mathrm{Ni}$ thin films.

3.3b Refractive index and extinction coefficient: The extinction coefficient $k(\lambda)$ of undoped and Ni-doped $\mathrm{ZnO}$ thin films (figure 6), was calculated using the following expression [35]:

$$
k=\frac{\alpha \lambda}{4 \pi} \text {. }
$$

The refractive index $n(\lambda)$ can be determined by using the envelopes of the transmittance $T(\lambda)$ of thin films deposited on a transparent substrate. The method of envelopes implies that the glass substrate is transparent [36]. The refractive index $n(\lambda)$ for various wavelengths and for curves envelopes $T_{\mathrm{M}}$ (for the maximum values of transmittance) and $T_{\mathrm{m}}$ (for the minimum values) is expressed by $[37,38]$ :

$$
n=\left[N+\left(N^{2}-S^{2}\right)^{1 / 2}\right]^{1 / 2},
$$

where

$$
N=2 S \frac{T_{\mathrm{M}}-T_{\mathrm{m}}}{T_{\mathrm{M}} T_{\mathrm{m}}}+\frac{s^{2}+1}{2} .
$$

Here, $S$ is the refractive index of the glass substrate. Figure 7 shows the refractive index $n$ for the undoped and Ni-doped $\mathrm{ZnO}$ thin films as a function of wavelength. The values of both $n$ and $k$ decrease with the increase in wavelength of the incident photon. In addition, the high values of $k$ in the fundamental absorption region (low wavelength $\lambda<400 \mathrm{~nm}$ ) are due to the intrinsic absorption for the higher energy gap. In the visible, the low values of $k$ imply that these layers are transparent as showed in the transmission spectra. It should be mentioned that in the wavelength range of 400 $800 \mathrm{~nm}$, the refractive index exhibits a normal dispersion and the extinction coefficient $k$ value is very low, the later confirming that of all the films studied in this work are homogeneous and highly transparent. A dependence on wavelength of the refractive index and the extinction coefficient with the doping concentration is observed. This phenomenon can be explained on the basis of the contribution from both lattice

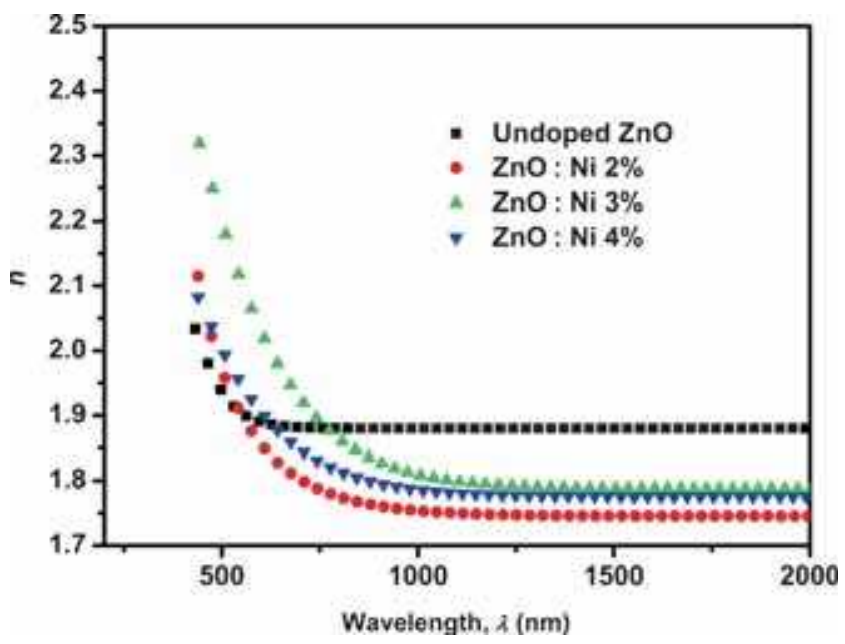

Figure 7. Refractive index $n$ of sprayed $\mathrm{ZnO}: \mathrm{Ni}$ thin films.

parameter change and the presence of defaults in the prepared films.

Owing to its straightforward link with the dispersion energy, the refractive index $n(\lambda)$ remains an important physical property of materials dedicated to optical devices. In order to achieve a better understanding of the refractive index dispersion of the Ni-doped $\mathrm{ZnO}$ thin films, $n(\lambda)$ was analysed by the single oscillator model proposed by Wemple and DiDomenico [39-42]. In this model, in the region of low absorption the photon energy dependence of the refractive index $n$ is expressed by

$$
n^{2}=1+\frac{E_{0} E_{\mathrm{d}}}{E_{0}^{2}-(h v)^{2}},
$$

where $E_{0}$ is the single oscillator energy and $E_{\mathrm{d}}$ the dispersion energy corresponding to the average strength of the interband optical transitions. $E_{0}$ and $E_{\mathrm{d}}$ are therefore determined through a linear fit of the plot of $1 /\left(n^{2}-1\right)$ as a function of $(h v)^{2}$ (figure 8). The slope is $\left(E_{0} E_{\mathrm{d}}\right)^{-1}$ and the intercept with the zero photon energy axis gives $\left(E_{0} / E_{\mathrm{d}}\right)$. The values of $E_{0}$ and $E_{\mathrm{d}}$ are reported in table 3 for all the films. Under the same model, the refractive index can also be analysed to determine the long wavelength refractive index $n_{\infty}$, average oscillator wavelength $\lambda_{0}$ and oscillator length strength $S_{0}$ of each thin film. These values can be obtained by using the following relations $[43,44]$ :

$$
\begin{aligned}
& \frac{n_{\infty}^{2}-1}{n^{2}-1}=1-\left(\frac{\lambda_{0}}{\lambda}\right)^{2}, \\
& n_{\infty}^{2}=1+S_{0} \lambda_{0}^{2}, \\
& n^{2}-1=\frac{S_{0} \lambda_{0}^{2}}{1-\left(\lambda_{0} / \lambda\right)^{2}},
\end{aligned}
$$

$n_{\infty}, S_{0}$ and $\lambda_{0}$ values are obtained from the linear of $1 /\left(n^{2}-1\right) v$ s. $\lambda^{-2}$ and are given in table 3 . It is found that, the nickel doping decreases the refractive index, $n_{0}$ and $\varepsilon_{\infty}$ for all films. 


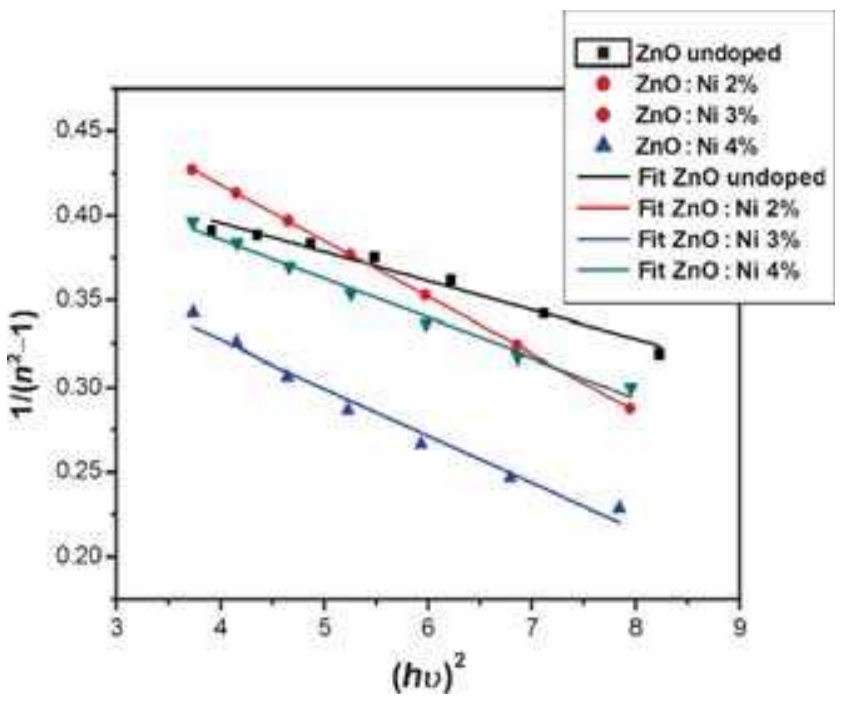

Figure 8. A plot of $\left(n^{2}-1\right)^{-1} v$ s. photon energy squared $(h v)^{2}$ of sprayed $\mathrm{ZnO}: \mathrm{Ni}$ thin films.

Table 3. Calculated values of $E_{0}, E_{\mathrm{d}}$ and other constants.

\begin{tabular}{lccccc}
\hline Samples & $E_{\mathrm{d}}(\mathrm{eV})$ & $E_{0}(\mathrm{eV})$ & $\lambda_{0}(\mu \mathrm{m})$ & $S_{0}\left(\mu \mathrm{m}^{-2}\right)$ & $n_{\infty}$ \\
\hline ZnO pure & 7.713 & 3.780 & 0.328 & 18.965 & 1.743 \\
ZnO : Ni 2\% & 7.687 & 4.194 & 0.295 & 20.971 & 1.683 \\
ZnO : Ni 3\% & 7.976 & 3.815 & 0.325 & 19.791 & 1.758 \\
ZnO : Ni 4\% & 8.949 & 4.446 & 0.278 & 25.875 & 1.735 \\
\hline
\end{tabular}

3.3c Dielectric constant: The optical characteristics of undoped and $\mathrm{Ni}$-doped $\mathrm{ZnO}$ are linked to its dielectric function too. The real $\varepsilon_{1}(\lambda)$ and the imaginary $\varepsilon_{2}(\lambda)$ parts of complex dielectric function are related to refractive index $n(\lambda)$ and extinction coefficient $k(\lambda)$ via the following relations $[44,45]$ :

$$
\begin{aligned}
& \varepsilon(\lambda)=(n(\lambda)-i k(\lambda))^{2}=\varepsilon_{1}(\lambda)-i \varepsilon_{2}(\lambda), \\
& \varepsilon_{1}(\lambda)=n(\lambda)^{2}-k(\lambda)^{2}, \\
& \varepsilon_{2}(\lambda)=2 n(\lambda) k(\lambda) .
\end{aligned}
$$

For all samples, it is found that in infrared range the dispersion of $\varepsilon_{1}$ is a linear function of the square of the wavelength $\lambda^{2}$ while the absorption $\varepsilon_{2}$ is a linear function of $\lambda^{3}$ (figure 9). This behaviour is in good agreement with the classical theory of the dielectric constant which is expressed by the following system in the near infrared $(\omega t \gg 1)$ [46]:

$$
\begin{aligned}
& \varepsilon_{1} \approx \varepsilon_{\infty}-\frac{\varepsilon_{\infty} \omega_{\mathrm{p}^{2}}}{4 \pi^{2} c^{2}} \lambda^{2}, \\
& \varepsilon_{2} \approx \varepsilon_{\infty}-\frac{\varepsilon_{\infty} \omega_{\mathrm{p}^{2}}}{8 \pi^{3} c^{3} \tau} \lambda^{3},
\end{aligned}
$$

where $\varepsilon_{\infty}$ is the dielectric constant at high frequencies, $\omega_{\mathrm{p}}$ the pulsation plasma and $\tau$ the relaxation time.

It can be seen that for all samples, in infrared range, $\varepsilon_{1}$ is a linear function of $\lambda^{2}$ while $\varepsilon_{2}$ is linear with $\lambda^{3}$.
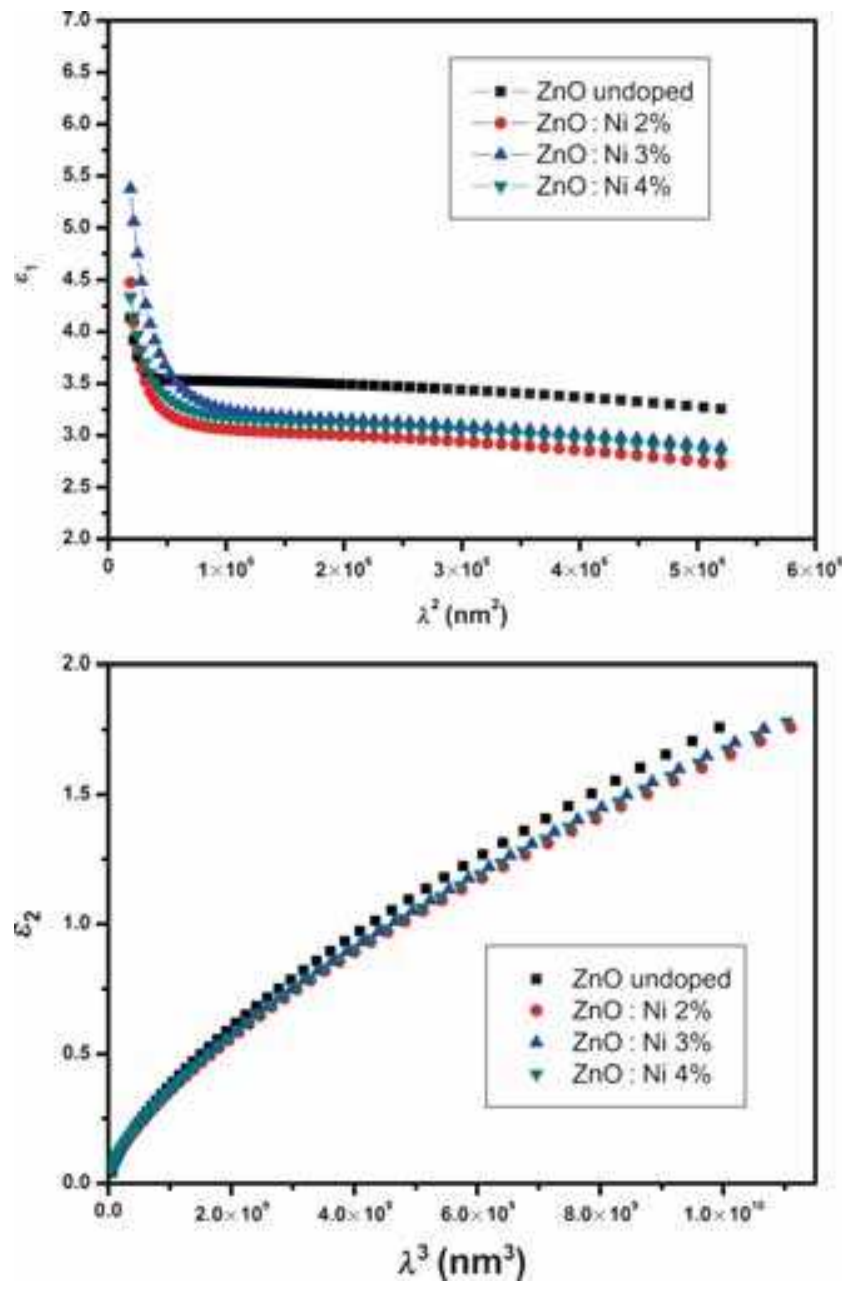

Figure 9. Variation of the real $\left(\varepsilon_{1}\right)$ and imaginary $\left(\varepsilon_{2}\right)$ parts and of dielectric constant of sprayed Ni-doped $\mathrm{ZnO}$ as a function of $\lambda^{2}$ and $\lambda^{3}$, respectively.

These results can be used in order to determine the optical constants: $\varepsilon_{\infty}, \omega_{\mathrm{p}}$ and $\tau$ which represent, respectively, the dielectric constant at high frequencies, the pulse plasma and the relaxation time which depends on the conduction mechanism of carriers in the optical and acoustic phonons, lattice defects and ionized impurities.

The free carrier's concentration-to-effective mass ratio $N / m^{*}$, is given from the system

$$
\omega_{\mathrm{p}}^{2}=\frac{4 \pi N \mathrm{e}^{2}}{\varepsilon_{\infty} m_{\mathrm{e}}^{*}} .
$$

The calculated values of these constants are listed in table 4 .

3.3d Photoluminescence: PL measurement is a sensitive nondestructive way to study the intrinsic and extrinsic defects in semiconductor materials. It delivers abundant information on the energy states of impurities and defects, even at very low densities, which is helpful for understanding structural defects in semiconductors. Moreover, it provides an additional insight into the crystal quality of semiconductor 
Table 4. Calculated values of $\varepsilon_{\infty}, \omega_{\mathrm{p}}$ and other constants.

\begin{tabular}{lcccc}
\hline Samples & $\varepsilon_{\infty}$ & $\omega_{\mathrm{p}}\left(10^{14} \mathrm{rad} \mathrm{s}^{-1}\right)$ & $\tau\left(10^{-14} \mathrm{~s}\right)$ & $\begin{array}{c}N / m^{*}\left(10^{47}\right. \\
\left.\mathrm{g}^{-1} \mathrm{~cm}^{-3}\right)\end{array}$ \\
\hline ZnO pure & 3.77 & 2.82 & 3.45 & 1.04 \\
$\mathrm{ZnO}: \mathrm{Ni} 2 \%$ & 5.04 & 14.98 & 1.07 & 40.99 \\
$\mathrm{ZnO}: \mathrm{Ni} 3 \%$ & 4.97 & 11.45 & 0.59 & 22.57 \\
$\mathrm{ZnO}: \mathrm{Ni} 4 \%$ & 4.86 & 15.46 & 1.06 & 40.99 \\
\hline
\end{tabular}

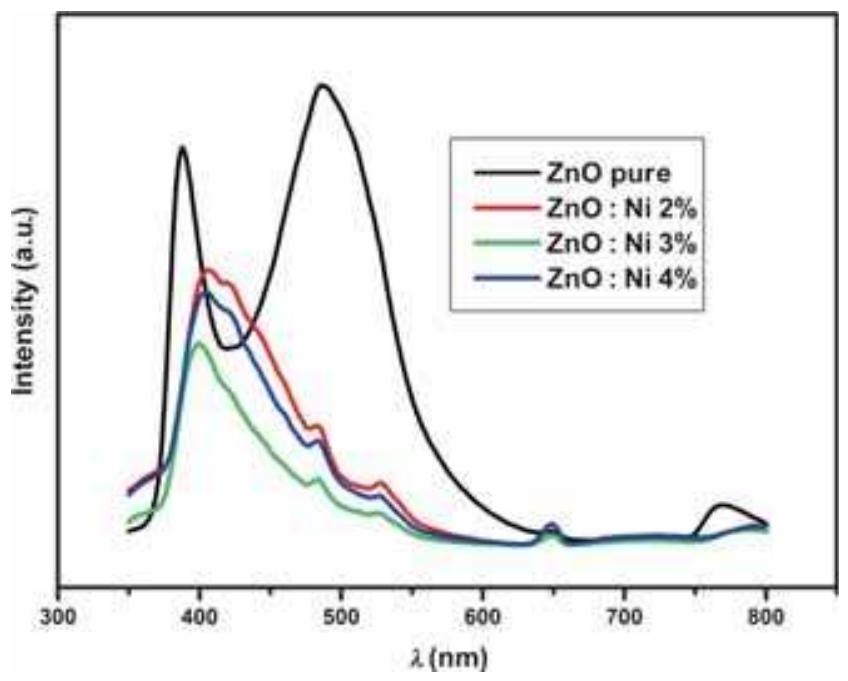

Figure 10. Room-temperature photoluminescence spectra of undoped and $\mathrm{Ni}$-doped $\mathrm{ZnO}$ thin films.

films through different emissions. Figure 10 shows roomtemperature PL spectra of undoped and Ni-doped $\mathrm{ZnO}$ thin films. A strong ultraviolet (UV) and blue-green emissions at around 387 and $488 \mathrm{~nm}$ are observed for undoped $\mathrm{ZnO}$ thin film. After Ni doping, the UV band emission shifts to $403 \mathrm{~nm}$ with the violet and blue-green emission bands are observed at 422,484 and $528 \mathrm{~nm}$, respectively.

The UV emission can be attributed to the near band edge (NBE) emission of $\mathrm{ZnO}$ and originated by the recombination of free exciton transition from the localized level below the conduction band to the valence band [47]. The band edge absorption peaks of $\mathrm{Ni}$-doped $\mathrm{ZnO}$ thin films shifts to longer wavelengths (red shifted). Different authors have explained that the red shift in $\mathrm{ZnO}$ band edge absorption peak with transition metals doping can be assigned to $\mathrm{sp}-\mathrm{d}$ spin exchange interactions between the band electrons of host matrix and the localized d-electrons of dopant ions substituting the cations [48-50]. They have discussed that s-d and $\mathrm{p}-\mathrm{d}$ exchange interactions can give rise to negative and positive shifts to the conduction band and valence band edges, respectively, which leads to the narrowing of band gap. Hence, it can be concluded that Ni doping induced red shift in the band edge absorption peak of $\mathrm{ZnO}$ is due, in this case, to the $\mathrm{sp}-\mathrm{d}$ exchange interactions. As the doping concentration increased the full-width half-maximum (FWHM) and the peak intensity of the UV emission decreased. Ni doping in $\mathrm{ZnO}$ causes creation of the defects, which might have provided non-radiative pathways to limit the radiative efficiency of the films. The visible emission from undoped and $\mathrm{Ni}$-doped $\mathrm{ZnO}$ thin films may be due to the defect, particularly the oxygen vacancy arising from the oxygen deficiency and both $\mathrm{O}$ and $\mathrm{Zn}$ interstitials [51]. A blue luminescence peak centred at $484 \mathrm{~nm}$ in visible region is observed for all the samples. The blue-green emission is caused by intrinsic defects and donor-acceptor pair recombination. Kohan et al [52] have calculated the energy levels of defects in $\mathrm{ZnO}$ thin films by a full-potential linear muffin-tin orbit method and shown that the energy interval between the $\mathrm{Zn}$ interstitial levels to the top of the valence band was about $2.9 \mathrm{eV}$. The luminescence centre $(\approx 2.6 \mathrm{eV})$ calculated in this work agrees quite well with Kohan's theoretical calculation. Therefore, the blue-green emission band is assigned to the electron transition from the $\mathrm{Zn}$ interstitial levels to the top of valence band. However, since the intensity of blue-green emission decreased in the nickel-doped samples it could be concluded that the defect states responsible for the broad blue-green emission in $\mathrm{ZnO}$ can be passivity by nickel.

\subsection{Opto-thermal expansivity study}

The Amlouk-Boubaker opto-thermal expansivity $\Psi_{\mathrm{AB}}$ is a thermo-physical parameter defined in precedent studies [53], as a $3 \mathrm{D}$ expansion velocity of the transmitted heat inside the material. It is expressed in $\mathrm{m}^{3} \mathrm{~s}^{-1}$, and calculated by

$$
\Psi_{\mathrm{AB}}=\frac{D}{\widehat{\alpha}}
$$

where $D$ is the thermal diffusivity and $\widehat{\alpha}$ the effective absorption, it is a weighted average of the absorption coefficient of the solar spectrum AM1.5. This parameter is shown as follows:

$$
\left\{\begin{array}{c}
\hat{\alpha}=\frac{\int_{0}^{1} I(\tilde{\lambda})_{\mathrm{AM} 1.5} \times \alpha(\tilde{\lambda}) \mathrm{d} \tilde{\lambda}}{\int_{0}^{1} I(\tilde{\lambda})_{\mathrm{AM} 1.5} \mathrm{~d} \tilde{\lambda}}, \\
\left\{\begin{array}{l}
\lambda \in\left[\lambda_{\min }, \lambda_{\max }\right] \Leftrightarrow \tilde{\lambda} \in[0,1] \\
\lambda_{\min }=300.0 \mathrm{~nm} ; \lambda_{\max }=1800.0 \mathrm{~nm}
\end{array}\right.
\end{array}\right.
$$

where $I(\tilde{\lambda})_{\text {AM1.5 }}$ is the reference solar spectral irradiance and the normalized absorbance spectrum $\alpha(\widetilde{\lambda})$ is deduced from the relation

$$
\alpha(\tilde{\lambda})=\frac{1}{d \sqrt[4]{2}} \cdot \sqrt[4]{\left(\ln \frac{1-R(\tilde{\lambda})}{T(\tilde{\lambda})}\right)^{4}+\left(2 \ln \frac{1-R(\tilde{\lambda})}{\sqrt{T(\tilde{\lambda})}}\right)^{4}},
$$

where $d$ is the layer thickness. This parameter is used to classify certain semiconductor thin films along their absorption of light [54]. The calculated values of $\Psi_{\mathrm{AB}}$ of Ni-doped $\mathrm{ZnO}$ thin films are summarized in table 5. In addition, the decrease of this parameter $\mathrm{Ni}$ content from 19.7 to $1476 \times 10^{-12} \mathrm{~m}^{3} \mathrm{~s}^{-1}$ 
Table 5. Values of the Amlouk-Boubaker opto-thermal expansivity $\Psi_{\mathrm{AB}}$.

\begin{tabular}{ccccc}
\hline & Undoped $\mathrm{ZnO}$ & $\mathrm{ZnO}: \mathrm{Ni} 2 \%$ & $\mathrm{ZnO}: \mathrm{Ni} 3 \%$ & $\mathrm{ZnO}: \mathrm{Ni} 4 \%$ \\
\hline$\Psi_{\mathrm{AB}}\left(10^{-12} \mathrm{~m}^{3} \mathrm{~s}^{-1}\right)$ & 19.7 & 15.8 & 14.53 & 14.76 \\
\hline
\end{tabular}

is noted. This effect shows the incorporation of Ni doping in the $\mathrm{ZnO}$ matrix. This decrease in $\Psi_{\mathrm{AB}}$ is in good agreement with the decrease in the film transparency and the increase in the optical absorption of such doped films.

\section{Conclusion}

The structural and the optical properties of Ni-doped $\mathrm{ZnO}$ thin films deposited by the spray pyrolysis technique was investigated. The influence of Ni doping on the structural, PL, morphological and optical properties was presented. Structural characterization reveals that $\mathrm{Ni}$ ions are successfully incorporated into the $\mathrm{ZnO}$ lattice without any extra phase and wurtzite structure of $\mathrm{ZnO}$ is retained. All of Nidoped $\mathrm{ZnO}$ films are highly transparent with a transmittance between 75 and $95 \%$ in the visible wavelength region. The high quality of the films is confirmed by the low value of the extinction coefficient. The optical band gap $E_{\mathrm{g}}$ of Ni-doped films exhibits a red shift.

In this study, the refractive-index dispersion was analysed using the single oscillator model. The Ni-doping affects the values of the calculated dispersion parameters such as oscillator energy, dispersion energy and oscillator strength. The results obtained by $\mathrm{PL}$ of sprayed $\mathrm{ZnO}$ thin films are discussed in terms of nickel content and it is found that they confirm those obtained by XRD. Finally, the behaviour of the dielectric constant components spectra needs more investigations particularly in infra-red region but beforehand that this result is quite encouraging since a costless and simple used depositing technique was considered.

\section{References}

[1] Gupta R K, Ghosh K and Kahol P K 2010 Mater. Lett. 641487

[2] Kakeno T, Sakai K, Komaki H, Yoshino K, Sakemi H, Awai K, Yamamoto T and Ikari T 2005 Mater. Sci. Eng. B 11870

[3] Hossain M M, Ku B-C and Hahn J R 2015 Appl. Surf. Sci. 354 55

[4] Neykova N, Hruska K, Holovsky J, Remes Z and Vanecek M 2013 Thin Solid Films 543110

[5] Mhamdi A, Labidi A, Souissi B, Kahlaoui M, Yumak A, Boubaker K, Amlouk A and Amlouk M 2015 J. Alloys Compd. 639648

[6] Han J, Gong H, Yang X, Qiu Z, Zi M, Qiu X, Wang H and Cao B 2015 Appl. Surf. Sci. 332549

[7] Mahdhi H, Ben Ayadi Z, Gauffier J L, Djessas K and Alaya S 2015 Opt. Mater. 4597

[8] Castro M V and Tavares C J 2015 Thin Solid Films 58613
[9] Zaier A, Meftah A, Jaber A Y, Abdelaziz A A and Aida M S 2015 J. King Saud Univ. — Sci. 27356

[10] Mhamdi A, Ouni B, Amlouk A, Boubaker K and Amlouk M 2014 J. Alloys Compd. $\mathbf{5 8 2} 810$

[11] Lee J-H, Ko K-H and Park B-O 2003 J. Cryst. Growth 247 119

[12] Omri K, El Ghoul J, Lemine O M, Bououdina M, Zhang B and El Mir L 2013 Superlattices Microstruct. 60139

[13] Mhamdi A, Boukhachem A, Madani M, Lachheb H, Boubaker K, Amlouk A and Amlouk M 2013 Optik 1243764

[14] Mhamdi A, Mimouni R, Amlouk A, Amlouk M and Belgacem S 2014 J. Alloys Compd. 610250

[15] Mimouni R, Kamoun O, Yumak A, Mhamdi A, Boubaker K, Petkova P and Amlouk M 2015 J. Alloys Compd. 645100

[16] Rajeh S, Mhamdi A, Khirouni K, Amlouk M and Guermazi S 2015 Opt. Laser Technol. 69113

[17] Liu X X, Lin F T, Sun L L, Cheng W J, Ma X M and Shi W Z 2006 Appl. Phys. Lett. 88062508

[18] Bodker F, Hansen M F, Koch C B and Morup S 2000 J. Magn. Magn. Mater. 22132

[19] Yilmaz S, McGlynn E, Bacaksız E, Cullen J and Chellappan R K 2012 Chem. Phys. Lett. 525-526 72

[20] Cheng C W, Xu G Y, Zhang H Q and Luo Y 2008 Mater. Lett. 621617

[21] Ghosh S, Srivastava P, Pandey B, Saurav M, Bharadwaj P, Avasthi D K, Kabiraj D and Shivaprasad S M 2008 Appl. Phys. A 90765

[22] Cong C J, Hong J H, Liu Q Y, Liao L and Zhang K L 2006 Solid State Commun. 138511

[23] Wu D W, Yang M, Huang Z B, Yin G F, Liao X M, Kang Y Q, Chen X F and Wang H 2009 J. Colloid Interface Sci. 330 380

[24] Kim K H, Jin Z, Abe Y and Kawamura M 2015 Mater. Lett. 1498

[25] Fang G, Li D and Yao B-L 2003 J. Cryst. Growth 247393

[26] Boukhachem A, Ouni B, Karyaoui M, Madani A, Chtourou R and Amlouk M 2012 Mater. Sci. Semicond. Proc. 15282

[27] Cullity B D 1978 Elements of X-ray diffraction (New York: Addison-Wesle Publishing Company)

[28] Kaeble E F 1967 Handbook of X-rays (New York: McGrawHill)

[29] Muniyandi I, Mani G K, Shankar P and Rayappan J B B 2014 Ceram. Int. 407993

[30] Zhang X, Li X M, Chen T L, Bian J M and Zhang C Y 2005 Thin Solid Films 492248

[31] Castaneda L, Silva-Gonzalez R, Gracia-Jimenez J M, Hernandez-Torres M E, Avendano-Alejo M, Marquez-Beltran C, de la L Olvera M, Vega-Perez J and Maldonado A $2010 \mathrm{~J}$. Mater. Sci. Semicond. Process. 1380

[32] Mill G, Li Z G and Meisel D 1988 J. Phys. Chem. 92822 
[33] Ghazi M E, Izadifard M, Ghodsi F E and Yuonesi M $2011 \mathrm{~J}$. Super-Cond. Nov. Magn. 25101

[34] Patil S K, Shinde S S and Rajpure K Y 2013 Ceram. Int. 39 3901

[35] Ben Rabeh M and Kanzari M 2011 Thin Solid Films 5197288

[36] Marquez E, Ramirez-Malo J B, Villares P, Jimenez-Garay R and Swanepoel R 1995 Thin Solid Films 25483

[37] Swanepoel R 1983 J. Phys. E: Sci. Instrum. 161214

[38] Swanepoel R 1984 J. Phys. E: Sci. Instrum. 17896

[39] Wemple S H and Didomenico M 1971 J. Phys. Rev. B 31338

[40] DiDomenico M and Wemple S H 1969 J. Appl. Phys. 40 720

[41] Wemple S H 1973 J. Phys. Rev. B 73767

[42] Lee P A, Said G, Davis R and Lim T H 1969 J. Phys. Chem. Solids 302719

[43] Gervais F 2002 Mater. Sci. Eng. R 3929

[44] Wolaton A K and Moss T S 1963 Proc. R. Soc. A 815091
[45] Omar M A 1993 Elementary solid state physics (New York: Addison-Wesley Publishing Company)

[46] Belgacem S and Bennaceur R 1990 Rev. Phys. Appl. 251245

[47] Cho S, Ma J, Kim Y, Sun Y, Wong G K L and Ketterson J B 1999 Appl. Phys. Lett. 752761

[48] Ahmed F, Kumar S, Arshi N, Anwar M S and Koo B H 2012 CrystEngComm 144016

[49] Chen Z C, Zhug L J, Wu X M and Meng Y D 2007 Thin Solid Films 5155462

[50] Kim K J and Park Y R 2004 J. Appl. Phys. 964150

[51] Zhao J, Hu L, Liu W and Wang Z 2007 Appl. Surf. Sci. 253 6255

[52] Kohan A F, Ceder G, Morgan D and Van de Walle C G 2000 Phys. Rev. B 6115019

[53] Tabatabaei S, Zhao T, Awojoyogbe O and Moses F 2009 Int. J. Heat Mass Transfer 451247

[54] Fridjine S and Amlouk M 2009 Phys. Lett. B 232179 